\title{
Review of the Marital Satisfaction Scale's Factor Structure
}

\author{
José Augusto Evangelho Hernandez ${ }^{1}$ \\ Camila Morais Ribeiro \\ Universidade do Estado do Rio de Janeiro, Rio de Janeiro, RJ, Brazil \\ Ana Lúcia Novais Carvalho \\ Universidade Federal Fluminense, Niterói, RJ, Brazil \\ Regina Coeli Tannus Fonseca \\ Faculdade Salesiana Maria Auxiliadora, Macaé, RJ, Brazil \\ Raphael Fischer Peçanha \\ Universidade Estácio de Sá, Rio de Janeiro, RJ, Brazil \\ Eliane Mary de Oliveira Falcone \\ Universidade do Estado do Rio de Janeiro, Rio de Janeiro, RJ, Brazil
}

\begin{abstract}
Marital satisfaction is a construct that is relevant to psychology research due to its significance in terms of establishing this interpersonal relationship. The present study examines the factor structure of the Marital Satisfaction Scale (MSS). The MSS has frequently been employed in Brazilian studies, incorporated as a convergent measure for producing criterion validity evidence in the elaboration of new psychometric methods. Nonetheless, its psychometric properties have not been substantiated for 25 years. A non-probabilistic sample of 249 people from Rio de Janeiro participated in the present study, their ages ranging between 21 and 77 years $(M=45.3 ; S D=13.26)$. They had been married or involved in a civil union (also known as a "domestic partnership" or "common-law marriage" depending on the location) for an average of 19.5 years $(S D=12.88)$. The collected data was assessed via exploratory and confirmatory factor analyses. Such assessment revealed several items exhibiting poor psychometric performance. Nevertheless, an abridged version of the MSS provided simplicity and produced excellent fit indices. It also yielded validity evidence of the existence of a second-order factor. The estimated reliability for both the factors and the entire scale ranged between 0.85 and 0.93 .
\end{abstract}

Keywords: Marital satisfaction, marital relationship, psychometric properties.

\section{Revisão da Estrutura Fatorial da Escala de Satisfação Conjugal}

\section{Resumo}

A satisfação conjugal é um construto relevante para o estudo na Psicologia, dada sua importância no desenvolvimento deste relacionamento interpessoal. Esta investigação revisou a estrutura fatorial da Escala de Satisfação Conjugal (ESC). A ESC, frequentemente, tem sido utilizada na pesquisa brasileira, inclusa como medida convergente para gerar evidências de validade de critério no desenvolvimento de novas medidas psicológicas. Por outro lado, suas propriedades psicométricas não são verificadas há 25

Mailing address: Rua São Francisco Xavier, 524, $10^{\circ}$ andar, sala 10028D, Maracanã, Rio de Janeiro, RJ, Brazil 20550-900. Phone: (21) 97252-8440. E-mail: hernandez.uerj@gmail.com 
anos. Participou deste estudo uma amostra não probabilística de 249 pessoas do Rio de Janeiro, com idades entre 21 e 77 anos $(M=45,3 ; D P=13,26)$, casadas ou em uniões estáveis há 19,5 anos em média $(D P=12,88)$. Os dados coletados foram submetidos às Análises Fatorial Exploratória e Confirmatória. $\mathrm{O}$ exame revelou alguns itens com desempenhos psicométricos insatisfatórios. Contudo, uma versão reduzida da ESC apresentou simplicidade e índices de ajuste estimados muito bons. Evidências de validade da existência de um fator de segunda ordem também foram produzidas. A fidedignidade estimada para os fatores e a escala toda variou de 0,93 a 0,85 .

Palavras-chave: Satisfação conjugal, relação conjugal, propriedades psicométricas.

\section{Revisión de la Estructura Factorial de la Escala de Satisfacción Marital}

\section{Resumen}

La satisfacción marital es un constructo relevante para el estudio de la psicología, dada su importancia en el desarrollo de esta relación íntima. Esta investigación examinó la estructura factorial de la Escala de Satisfacción Marital (MSS). El MSS menudo se ha utilizado en la investigación brasileña, incluso como medida para generar criterio de validez convergente en el desarrollo de nuevas medidas psicológicas. Por otro lado, las propiedades psicométricas no se examinan hace 25 años. Participaron en este estudio una muestra no probabilística de 249 personas de Río de Janeiro, 21-77 años de edad ( $M=45.3, D E=$ 13.26), casadas o en unión estable con 19,5 años de media $(D E=12.88)$. Los datos fueron sometidos a un análisis factorial exploratorio y confirmatorio. El examen reveló algunos ítems con actuaciones psicométricas pobres. Sin embargo, una versión reducida de la MSS presentó sencillez y los índices de ajuste estimados muy buenos. También se produjeron evidencia de la validez de la existencia de un factor de segundo orden. La fiabilidad estimada para los factores y la escala completa variaron desde 0.93 hasta 0.85 .

Palabras clave: Satisfacción marital, relación matrimonial, propriedades psicométricas.

The present study assessed the factor structure of the Brazilian version of Pick de Weiss and Andrade Palos' (1988a) Marital Satisfaction Scale (MSS) (Dela Coleta, 1989). In Brazilian psychology research, this scale has even been used as a convergent measure to provide criterion validity evidence for recently established measurement standards (1988a). Nonetheless, ever since the MSS was adapted (over 25 years ago), no assessments of the scale's psychometric status have appeared in the literature (1988a).

Marital satisfaction is a subject that receives broad coverage in the scientific literature of the field of Psychology. Individuals that are satisfied with their marriages exhibit better health than those who are disappointed with their relationships do (Gottman \& Silver, 2000). One issue that strongly stands out is the connection between marital satisfaction, happiness and per- sonal wellbeing (Machado, 2007; Scorsolini-Comin \& Santos, 2011a, 2012). Conversely, poor marriage relations seem to be associated with the development of physical and mental maladies (Gottman \& Silver, 2000), to the disadvantage of relations with relatives (Benetti, 2006; Bolsoni-Silva \& Marturano, 2010), family members in general and friends (Norgren, Souza, Kaslow, Hammerschmidt, \& Sharlin, 2004). Personality traits (Solomon \& Jackson, 2014), gender (Jackson, Miller, Oka, \& Henry, 2014), the existence of offspring (Hernandez \& Hutz, 2009), education (Mihalcea, Iliescu, \& Dincă, 2013), social and financial status (Ahmadi \& Sadeghi, 2016), working for a living (Minnotte, Minnotte, \& Pedersen, 2013), prior amorous experiences (Mirecki, Chou, Elliott, \& Schneider, 2013), and the dynamics and changes brought by time (Norgren et al., 2004) can all affect the situation, 
increasing or decreasing a couple's marital satisfaction, depending upon each particular case.

Pick de Weiss and Andrade Palos (1988a) viewed marital satisfaction as a series of attitudes in relation to factors associated with spouses and marital interactions. These authors advocated the need to establish Mexico's own marital satisfaction scale in light of the fact that most of the existing scales employed global satisfaction criteria and in general represented the Anglo-Saxon culture. They thus created a marital satisfaction scale (MSS) based on the Hispanic culture.

The preliminary study aimed at developing the Hispanic MSS version involved the participation of 330 married individuals (176 women and $154 \mathrm{men}$ ) with the following averages: age, 36.3 years; length of the marriage, 13.9 years; and number of children, 3.1 (Pick de Weiss \& Andrade Palos, 1988a). After analyzing the frequencies of the MSS participants' scores, 37 items were chosen that, when subjected to Principal Component Analysis (PCA) with oblique rotation, had led to six factors with eigenvalues $>1.0$, which explained $58.1 \%$ of the total variance. Employing conceptual criteria, the first three factors that accounted for $47.8 \%$ of the total variance were retained and 14 items were excluded. Based on an analysis of the content of the remaining 23 items, the following factors were selected:

1. Satisfaction with Marital Interaction (SMI), which denotes the individual's satisfaction with respect to the relationship with her/his partner;

2. Satisfaction with Emotional Aspects (SEA), which refers to the individual's satisfaction with his/her partner's emotional reactions (e.g., how the partner expresses feelings and behaves when angry or nervous); and

3. Satisfaction with Structural Aspects (SSA), which relates to the individual's satisfaction with his/her partner's way of organizing, establishing and complying with rules (e.g., how the partner organizes his/her own life) and its impact on the individual's life.

The second study (Pick de Weiss \& Andrade Palos, 1988a) enjoyed the participation of 244 married individuals (139 women and 105 men) from Mexico City with the following averages: age, 31.5 years; length of the marriage, 8.7 years; and number of children, 1.7. Eleven new items were added to the 23 previously selected MSS items (the reason for this inclusion was not given). The researchers conducted a second PCA with oblique rotation and extracted seven factors with eigenvalues $>1.0$, which explained $49.7 \%$ of the total variance. Aiming at conceptual clarity, the researchers retained the first three extracted factors that accounted for $45.7 \%$ of the total variance. The rotated matrix of the factor loadings of the items was not presented in the results, but 10 items were excluded and the MSS came to be made up of 24 items distributed among three factors. The alphas obtained for the factors were 0.90 for SMI (10 items), 0.81 for SEA ( 5 items), and 0.85 for SSA ( 9 items).

Noteworthy statistical connections $(p<.05)$ between MSS subscales and several sociodemographic variables were discovered (Pick de Weiss \& Andrade Palos, 1988a, 1988b, 1988c). Males exhibited mean scores $>$ those of females with respect to SMI and SSA. People with the shortest relationships (one to two years) displayed SMI levels $>$ those of people with relationships of 16 or more years. In general, individuals with three or more children exhibited SMI, SEA, and SSA levels that were lower than were those of people with one, two, or no children. The higher the educational level of the participant, the higher the SMI scores were. The individuals' ages did not display a statistically significant connection with any of the three MSS subscales.

Considering the Hispanic version of the MSS a gauge of culture similar to Brazilian culture, Dela Coleta (1989) created a Brazilian version of the Hispanic Marital Satisfaction Scale (MSS). Dela Coleta analyzed the MSS scores of 206 individuals (90 men and 117 women) who had been married for at least five years and had at least one child. The participants' ages varied between 23 and 65 years, and their socioeconomic and educational levels were diverse. The examinees were residents of two cities - one of them medium-sized; and the other, large - in Brazil's interior. Subsequent to simple translation procedures and validation of the content of 
the Brazilian version, the data collected in the MSS was subjected to PCA with varimax rotation. A five-factor solution with eigenvalues $>$ 1.0 was extracted, which explained $57.2 \%$ of the total variance. The items loaded in the fourth and fifth factors were allocated in the original threefactor structure based on the content of the same and on the scree plot.

A PCA with varimax rotation for three factors was then performed, accounting for $48.3 \%$ of the total variance. Nonetheless, three items from the SSA subscale ("The way my spouse spends his/her spare time," "The time we spend together," and "The rules my spouse establishes to be followed at home") and one item from the SEA subscale ("How my spouse reacts when I don't want to have sex") exhibited greater saturation with respect to SMI. The author recommended that future studies check the possibility both of reallocating these items where they were more saturated and of redefining the configuration of each one of the MSS's three dimensions. Furthermore, the correlations between the three factors as well as the internal consistency coefficients obtained for them led her to consider a general marital satisfaction scale (Dela Coleta, 1989).

PCA was the extraction method employed to elaborate (Pick de Weiss \& Andrade Palos, 1988a) and adapt (Dela Coleta, 1989) the MSS. Although it is not an authentic factor-analysis technique, it is found in the most popular statistics packages as the default extraction method, which could partially explain its indiscriminate use. PCA does not distinguish common variance between factors from total variance; and, in certain situations, it could overestimate the variance explained by the components (Costello \& Osborne, 2005; Ferrando \& Anguiano-Carrasco, 2010). A considerable amount of the psychometric research published in major psychology journals still employs Principal Component Analysis (PCA) inappropriately to conduct exploratory tasks (Conway \& Huffcutt, 2003; Gaskin \& Happell, 2014; Henson \& Roberts, 2006; Left, Olea, \& Abad, 2014).

Exploratory Factor Analysis (EFA) is more appropriate than PCA for preparing and validat- ing psychological tests. This method examines latent variables and common factors that explain research subjects' responses to the items of a psychological survey (Damásio, 2012; Ferrando \& Anguiano-Carrasco, 2010; Izquierdo et al., 2014; Laros, 2005; Lloret-Segura, FerreresTraver, Hernández-Baeza, \& Tomás-Marco, 2014).

The Brazilian adaptation of the Hispanic MSS (Dela Coleta, 1989) employed an orthogonal rotation. Currently, the use of oblique rotations, independent of theoretical presumptions as to the relationships between the constructs, is recommended. This recommendation is based on the fact that perfect orthogonal relationships cannot be found in Psychology (Lloret-Segura et al., 2014).

Traditional decision-making approaches to factor retention (eigenvalues and scree plots) are currently considered unsatisfactory (Lorenzo-Seva, Timmerman, \& Kiers, 2011). Parallel Analysis has consistently exhibited greater precision than conventional methods have for guiding factor-retention decisions (Gaskin \& Happell, 2014).

Dela Coleta's criterion (1989) for selecting the items for each factor in a rotated factor matrix was that the item's loading had to be $>0.30$. Nevertheless, this criterion took into consideration the principal loadings alone, to the detriment of the values of associated saturations in other factors. Seven items with cross-loadings were detected. Lacking theoretical justifications for retaining such items in the MSS, they can be excluded or rephrased (Hair, Black, Babin, Anderson, \& Tatham, 2009).

In order to check the status of MSS use in Brazilian studies, a bibliographic examination of the Literatura Latino-Americana e do Caribe em Ciências da Saúde (LILACS) and Scientific Electronic Library Online (SciELO) databases was conducted focusing on articles published between 1989 and 2015 in Brazil. The search terms employed were "satisfação conjugal" [marital satisfaction, in Portuguese] and "marital satisfaction." Only reports of empirical studies that actually used the MSS in the research were considered. Eight articles were selected (Dela 
Coleta, 1992; Oliveira, Falcone, \& Ribas, 2009; Ribeiro, Pinho, \& Falcone, 2011; Sardinha, Falcone, \& Ferreira, 2009; Sbicigo \& Lisboa, 2009; Scorsolini-Comin \& Santos, 2011a; ScorsoliniComim \& Santos, 2011b; Villa \& Del Prette, 2013). These articles brought to light the fact that, subsequent to the MSS's Brazilian adaptation (Dela Coleta, 1989), no research aimed at examining the MSS's psychometric features was conducted.

In light of this situation, the present study aimed to discover evidence of structural validity with respect to the scale's scores nowadays, employing statistical methods currently advocated by psychometric researchers (Gaskin \& Happell, 2014; Izquierdo et al., 2014; Lloret-Segura et al. Al., 2014). What is the MSS's psychometric status today? This is the question the present study sought to answer.

\section{Method}

\section{Participants}

We assessed the MSS scores of a convenience sample of 249 individuals from the state of Rio de Janeiro; it consisted of 151 women $(60.6 \%)$ and 98 men (39.4\%), with ages ranging between 21 and 77 years, an average age of 45.3 years and a standard deviation of 13.26 years. All of these individuals lived together with their spouses and were involved in a marital relationship, a marriage or a civil union (also known as a "domestic partnership" or "common-law marriage" depending on the location). The length of their relationships varied between 1 and 51 years, with an average duration of 19.5 years and a standard deviation of 12.88 years. Of the total sample (249 participants), 225 (90.4\%) stated that they were going through their first marriage; and 24 of them $(9.6 \%)$, their second marriage. The number of children declared by the examinees ranged from 0 to 7 , with a mean of 1.7 and a standard deviation of 1.11. Of the total, 44 (17.7\%) had no children, 55 (22.1\%) had only one, 103 (41.4\%) had two, 37 (14.9\%) had three, eight $3.2 \%$ ) had four, one $(0.4 \%)$ had five and one $(0.4 \%)$ had seven. $149(59.8 \%)$ of the sample's 249 participants declared they had a university degree, 33 (13.3\%) had an incomplete university education, $54(21.7 \%)$ had graduated from high school, $9(3.6 \%)$ had not finished high school, $3(1.2 \%)$ had finished elementary school, and $1(0.4 \%)$ did not provide this data.

\section{Instrument}

Dela Coleta's Brazilian version (1989) of the Marital Satisfaction Scale (MSS) created by Pick de Weiss and Andrade Palos (1988a) was examined. The MSS provides a general Marital Satisfaction (MS) measurement consisting of three factors or dimensions:

1. Satisfaction with Marital Interaction (SMI), featuring 10 items, which denotes the individual's satisfaction with respect to the relationship with her/his partner;

2. Satisfaction with Emotional Aspects (SEA), featuring five items, which refers to the individual's satisfaction with his/her partner's emotional reactions; and

3. Satisfaction with Structural Aspects (SSA), featuring nine items, which measures the individual's satisfaction with his/her partner's way of organizing, establishing and complying with rules and its impact on the individual's life. All 24 items were rated using a three-point Likert scale: (1) "I wish it were really different"; (2) "I wish it were a bit different"; and (3) "I like the way it has been".

\section{Data Collection}

This project was approved (via decision no. 096/2011) by the Ethics Committee of the institution with which the present study is associated. The individuals that were invited to participate in the study received complete information as to its objectives and signed an informed consent form. In most cases, the data was collected at the participants' homes. We gained access to these individuals via referrals or snowball sampling. Some of them answered the MSS questionnaire in the presence of the researchers; the others filled it out and returned it later. In both cases, the completed form was returned directly to the researchers. 


\section{Data Analysis}

Analysis of MSS score distribution revealed asymmetries of -1.325 to 0.110 and a kurtosis of -1.276 to 0.764 ; no extreme values were identified. Mardia's multivariate normality test (1970) yielded $50.12($ c.r. $=14.74)$. Since responses to the MSS are made via a three-point Likert scale, we opted for using a polychoric correlation matrix (Dominguez Lara, 2014).

The data was analyzed with the Factor 10.3.01 program (Lorenzo-Seva \& Ferrando, 2015) by means of Exploratory Factor Analysis (EFA) using the Unweighted Least Squares (ULS) estimation method and direct oblimin rotation. In order to determine the number of factors to be extracted, we used Parallel Analysis based on Minimum Rank Factor Analysis (Timmerman \& Lorenzo-Seva, 2011).

With the aim of confirming the existence of a supposed second-order factor (Dela Coleta, 1989), the factor-loading matrix was also subjected to Hierarchical Factor Analysis, the Schmid and Leiman solution (SSL, 1957). The SSL, which is a transformation of the matrices of factor loadings obtained in the first-order factor analysis, furnished additional information demonstrating the first- and second-order factors' influence (in an independent, non-superimposed manner) on the observed variables (Wolff \& Preising, 2005).

The MSS's original structural model (Dela Coleta, 1989) - with 24 items, three first-order factors and one second-order dimension - was also tested, by way of Confirmatory Factor Analysis (CFA) with Maximum Likelihood Estimation (MLE) and bootstrap replication, in the AMOS 18 app (Arbuckle, 2009). Seeking structural adequacy, we employed the following indices: the global fit of the model $\left(\chi^{2} / d f\right.$ ratio, which according to Byrne (2000) should be $>2.0$ to denote a good fit); the Goodness of Fit Index (GFI) of covariances between the variables detected by the model and the Comparative Fit Index (CFI) - both of which should exhibit values between 0.90 and 0.95 for a good fit (Marôco, 2014); the Root Mean Square Error of Approximation (RMSEA), which tests the fit between the model tested and a model saturated with the same data
- the index should be $<0.08$ for an acceptable fit and $<0.05$ for a very good fit (Marôco, 2014); and the Akaike Information Criterion (AIC) and the Consistent Akaike Information Criterion (CAIC), which are used in the comparison and penalize a model's complexity - the model exhibiting the lowest amounts has the best fit (Byrne, 2010).

\section{Results}

The Exploratory Factor Analysis employing the ULS estimation method and direct oblimin rotation revealed a solution of five factors with eigenvalues $>1.0$. On the other hand, the Parallel Analysis based on Minimum Rank Factor Analysis (Timmerman \& Lorenzo-Seva, 2011) indicated the retention of three factors. In the factor matrix of the new EFA for three factors, we identified several structural problems that were incompatible with the original model (Pick de Weiss \& Andrade Palos, 1988a). We noticed that the item "The time my spouse dedicates to our marriage" displayed a factor loading of 0.19 for the SMI dimension (for which it was designated), -0.04 for SEA, and 0.67 for SSA. The SMI item "My spouse's behavior in the presence of other people" exhibited factor loadings of 0.06 for SMI, 0.32 for SEA, and 0.30 for SSA. The SMI item "The time my spouse devotes to me" was saturated with loadings of 0.33 for SMI, 0.01 for SEA, and 0.59 for SSA. The SEA item "My spouse's reaction when I don't want to have sex" exhibited loadings of 0.34 for SEA, -0.05 for SSA, and 0.36 for SMI. The SSA item "The time we spend together" exhibited saturations of 0.38 for SSA, 0.07 for SEA, and 0.32 for SMI. The SSA item "The way my spouse seeks to solve problems" displayed loading saturations of 0.46 for SSA, 0.34 for SEA, and 0.16 for SMI.

The six items above were excluded according to Hair et al. (2009), and another EFA (employing the same method as above) was conducted with respect to the remaining 18 items. The KMO test yielded a value of 0.85 (considered good), and the Bartlett Sphericity Test produced the values $\chi^{2}(153)=1,463.90$ and $p$ $<.001$, both tests demonstrating the data's suit- 
Table 1

Polychoric Correlation Matrix of MSS Items

\begin{tabular}{|c|c|c|c|c|c|c|c|c|c|c|c|c|c|c|c|c|c|c|}
\hline Items & 2 & 3 & 4 & 5 & 6 & 8 & 9 & 11 & 12 & 13 & 14 & 15 & 16 & 17 & 19 & 20 & 21 & 24 \\
\hline 2 & 1.00 & & & & & & & & & & & & & & & & & \\
\hline 3 & 0.51 & 1.00 & & & & & & & & & & & & & & & & \\
\hline 4 & 0.73 & 0.39 & 1.00 & & & & & & & & & & & & & & & \\
\hline 5 & 0.54 & 0.32 & 0.39 & 1.00 & & & & & & & & & & & & & & \\
\hline 6 & 0.61 & 0.62 & 0.54 & 0.42 & 1.00 & & & & & & & & & & & & & \\
\hline 8 & 0.37 & 0.39 & 0.55 & 0.23 & 0.45 & 1.00 & & & & & & & & & & & & \\
\hline 9 & 0.35 & 0.34 & 0.29 & 0.22 & 0.35 & 0.18 & 1.00 & & & & & & & & & & & \\
\hline 11 & 0.19 & 0.37 & 0.24 & 0.09 & 0.49 & 0.34 & 0.34 & 1.00 & & & & & & & & & & \\
\hline 12 & 0.30 & 0.42 & 0.26 & 0.20 & 0.44 & 0.34 & 0.40 & 0.80 & 1.00 & & & & & & & & & \\
\hline 13 & 0.26 & 0.34 & 0.22 & 0.25 & 0.40 & 0.23 & 0.30 & 0.73 & 0.72 & 1.00 & & & & & & & & \\
\hline 14 & 0.38 & 0.46 & 0.36 & 0.21 & 0.49 & 0.28 & 0.26 & 0.65 & 0.76 & 0.63 & 1.00 & & & & & & & \\
\hline 15 & 0.31 & 0.24 & 0.06 & 0.31 & 0.21 & 0.15 & 0.32 & 0.13 & 0.17 & 0.15 & 0.20 & 1.00 & & & & & & \\
\hline 16 & 0.36 & 0.40 & 0.24 & 0.28 & 0.47 & 0.29 & 0.39 & 0.26 & 0.23 & 0.19 & 0.20 & 0.60 & 1.00 & & & & & \\
\hline 17 & 0.31 & 0.43 & 0.18 & 0.25 & 0.44 & 0.23 & 0.38 & 0.29 & 0.33 & 0.28 & 0.28 & 0.36 & 0.65 & 1.00 & & & & \\
\hline 19 & 0.24 & 0.27 & 0.08 & 0.25 & 0.20 & 0.08 & 0.11 & 0.20 & 0.22 & 0.14 & 0.20 & 0.38 & 0.26 & 0.19 & 1.00 & & & \\
\hline 20 & 0.24 & 0.08 & 0.21 & 0.16 & 0.24 & 0.06 & 0.46 & 0.21 & 0.23 & 0.19 & 0.33 & 0.26 & 0.30 & 0.28 & 0.23 & 1.00 & & \\
\hline 21 & 0.45 & 0.55 & 0.51 & 0.42 & 0.57 & 0.47 & 0.28 & 0.39 & 0.35 & 0.38 & 0.37 & 0.25 & 0.38 & 0.38 & 0.28 & 0.23 & 1.00 & \\
\hline 24 & 0.35 & 0.41 & 0.22 & 0.13 & 0.30 & 0.26 & 0.30 & 0.36 & 0.37 & 0.31 & 0.37 & 0.42 & 0.42 & 0.39 & 0.20 & 0.27 & 0.47 & 1.00 \\
\hline
\end{tabular}

Table 2

Parallel Analysis based on Minimum Rank Factor Analysis

\begin{tabular}{cccc}
\hline Variables & \multicolumn{3}{c}{$\%$ Variance } \\
\cline { 2 - 4 } & Current Data & Random Average & Random 95 $5^{\text {th }}$ Percentile \\
\hline 1 & $41.5^{* *}$ & 11.5 & 12.8 \\
2 & $11.7^{* *}$ & 10.5 & 11.5 \\
3 & $9.7^{*}$ & 9.6 & 10.6 \\
4 & 6.0 & 8.9 & 9.6 \\
\hline
\end{tabular}

Note. Results obtained from 500 random polychoric correlation matrices [raw data permutation method] (Buja \& Eyuboglu, 1992). ${ }^{* *}$ Number of factors recommended when $95^{\text {th }}$ percentile is considered. ${ }^{*}$ Number of factors recommended when mean is considered.

ability for factor analysis. The polychoric correlation matrix of the items can be seen in Table 1. We extracted five factors with eigenvalues $>$ 1.0. Parallel Analysis based on Minimum Rank Factor Analysis (Timmerman \& Lorenzo-Seva, 2011) upheld the suggestion to retain three factors (Table 2).
All 18 items of the condensed version exhibited greater saturation for the factors for which they were assigned in the theoretical model; 12 of them exhibited factor loadings $>0.50$, from reasonable to excellent (Hair et al., 2009). The SSA factor ended up with seven items, SMI with seven, and SEA with four. The estimated reli- 
ability for all factors and the global scale (MSS) varied between 0.85 and 0.93 (Table 3).

Bentler's Simplicity Index (1977) was 0.99 (100th percentile) and the Loading Simplicity Index (Lorenzo-Seva, 2003) was 0.52 (100th percentile). Such values pointed to the fact that each item mainly represents a single dimension, and the global solution displayed a high level of simplicity. The Root Mean Square of Residuals (RMSR) was 0.0520, while the average value expected for an acceptable model is $\leq 0.0635$, according to Kelley's criterion (1935).

Table 3

Factor Loadings of EFA with Direct Oblimin Rotation of MSS Items and Communalities

\begin{tabular}{llrrrr}
\hline & Items & SSA & SMI & SEA & $h^{2}$ \\
\hline 16 & My spouse's priorities in life & $\mathbf{0 . 8 2}$ & 0.06 & -0.06 & 0.69 \\
15 & The way my spouse organizes his/her life and things & $\mathbf{0 . 7 7}$ & -0.08 & -0.06 & 0.52 \\
17 & The way my spouse spends her/his time & $\mathbf{0 . 6 0}$ & 0.04 & 0.13 & 0.45 \\
24 & The rules my spouse establishes to be followed at home & $\mathbf{0 . 4 4}$ & 0.06 & 0.24 & 0.36 \\
09 & The time my spouse dedicates to him/herself & $\mathbf{0 . 3 9}$ & 0.09 & 0.21 & 0.31 \\
20 & How my spouse cares for her/his own health & $\mathbf{0 . 3 7}$ & 0.01 & 0.15 & 0.19 \\
19 & My spouse's punctuality & $\mathbf{0 . 3 5}$ & 0.03 & 0.07 & 0.16 \\
04 & The frequency with which my spouse hugs me & -0.15 & $\mathbf{0 . 9 3}$ & -0.03 & 0.76 \\
02 & The frequency with which my spouse says something nice to me & 0.16 & $\mathbf{0 . 7 7}$ & -0.06 & 0.67 \\
06 & The communication with my spouse & 0.16 & $\mathbf{0 . 5 7}$ & 0.24 & 0.62 \\
08 & The way my spouse asks me to have sexual relations & -0.01 & $\mathbf{0 . 5 1}$ & 0.14 & 0.34 \\
21 & My spouse's interest in what I do & 0.29 & $\mathbf{0 . 5 0}$ & 0.17 & 0.51 \\
05 & The attention my spouse pays to my appearance & 0.21 & $\mathbf{0 . 4 7}$ & -0.07 & 0.31 \\
03 & How well my spouse takes care of me & 0.22 & $\mathbf{0 . 4 3}$ & 0.22 & 0.47 \\
12 & How my spouse behaves when upset & 0.01 & -0.02 & $\mathbf{0 . 9 2}$ & 0.84 \\
11 & How my spouse behaves when sad & -0.01 & -0.05 & $\mathbf{0 . 9 1}$ & 0.79 \\
13 & How my spouse behaves when worried & -0.01 & 0.01 & $\mathbf{0 . 7 9}$ & 0.62 \\
14 & How my spouse behaves when in a bad mood & -0.01 & 0.14 & $\mathbf{0 . 7 3}$ & 0.63 \\
Explained Variance & 2.75 & 3.08 & 3.41 & \\
F2 & Variance Percentage (\%) & 29.8 & 33.3 & 36.9 & \\
F3 & Cstimated Reliability & 0.84 & 0.89 & 0.93 & \\
\hline & & & & & \\
& & 0.42 & & & \\
& & 0.36 & 0.41 & & \\
\hline & & & & & \\
& & &
\end{tabular}

Note. Unweighted Least Squares extraction method. In bold, the strongest factor loadings of items on factors.

In Table 4 (SSL results), one can notice such direct connections (factor loadings) between the observed variables, the first-order (SEA, SMI and SSA) and second-order (G1) factors, in an independent manner. In the analysis of the SSL factor loadings (Table 4), it can be observed that the MSS items' saturations are sufficient to simultaneously represent both their specific dimensions (SEA, SMI and SSA) and the global dimension, Marital Satisfaction (G1). Items 19 
and 20 are exceptions: the former reveals saturations that are insufficient to represent the specific (SSA) and general dimensions; and the latter displays an SSA factor loading that is lower than the minimum acceptable to represent its specific dimension, whereas its G1 loading is sufficient to represent the general dimension.

Table 4

SSL Factor Loadings for First- and Second-Order MSS Factors

\begin{tabular}{|c|c|c|c|c|c|}
\hline & Items & SSA & SMI & SEA & G1 \\
\hline 16 & My spouse's priorities in life & 0.66 & 0.04 & -0.04 & 0.50 \\
\hline 15 & The way my spouse organizes his/her life and things & 0.61 & -0.06 & -0.05 & 0.37 \\
\hline 17 & The way my spouse spends her/his time & 0.48 & 0.03 & 0.10 & 0.46 \\
\hline 24 & The rules my spouse establishes to be followed at home & 0.35 & 0.04 & 0.19 & 0.45 \\
\hline 09 & The time my spouse dedicates to him/herself & 0.31 & 0.06 & 0.17 & 0.42 \\
\hline 20 & How my spouse cares for her/his own health & 0.29 & 0.01 & 0.12 & 0.31 \\
\hline 19 & My spouse's punctuality & 0.28 & 0.02 & 0.06 & 0.28 \\
\hline 04 & The frequency with which my spouse hugs me & -0.12 & 0.67 & -0.03 & 0.53 \\
\hline 02 & The frequency with which my spouse says something nice to me & 0.13 & 0.55 & -0.05 & 0.59 \\
\hline 06 & The communication with my spouse & 0.13 & 0.41 & 0.19 & 0.63 \\
\hline 08 & The way my spouse asks me to have sexual relations & -0.01 & 0.37 & 0.11 & 0.43 \\
\hline 21 & My spouse's interest in what I do & 0.17 & 0.36 & 0.13 & 0.57 \\
\hline 05 & The attention my spouse pays to my appearance & 0.16 & 0.34 & -0.05 & 0.41 \\
\hline 03 & How well my spouse takes care of me & 0.18 & 0.31 & 0.18 & 0.56 \\
\hline 12 & How my spouse behaves when upset & 0.01 & -0.01 & 0.74 & 0.54 \\
\hline 11 & How my spouse behaves when sad & -0.01 & -0.04 & 0.73 & 0.50 \\
\hline 13 & How my spouse behaves when worried & -0.01 & 0.01 & 0.63 & 0.47 \\
\hline 14 & How my spouse behaves when in a bad mood & -0.01 & 0.10 & 0.58 & 0.53 \\
\hline G1 & $\mathrm{MSS}_{\text {total }}$ & 0.60 & 0.69 & 0.60 & \\
\hline
\end{tabular}

Note. G1= Global Dimension. In bold, the strongest factor loadings of items on specific factors and overall factor.

Seeking to corroborate the results obtained through the exploratory analysis, the original (24 items) and condensed (18 items) MSS models - both of which possess one second-order dimension and three first-order dimensions - were tested and compared via CFA (Figure 1). Considering the estimated indices, the values of the reduced model evidence a better fit than those of the original model (Table 5).

]The Pearson Correlation Coefficient revealed no statistically significant connections between the factors SMI, SEA, SSA \& MSS $_{\text {total }}$ and the length of the relationships or ages of the participants. In contrast, significant negative correlations between the ages $(r=-0.20, p<.01)$, the lengths of the relationships $(r=-0.16, p<$ .05 ) and the SMI factors were observed for the female participants.

Student's $t$-test for independent samples $\left(t_{(247)}=2.879, d=0.37\right)$ revealed considerable statistical differences $(p<.01)$ between the mean scores of men (2.47) and women (2.29) in relation to the SSA factor. With respect to the SMI, SEA and MSS $_{\text {total }}$ factors, no gender-related differences were observed and all of the values of the calculated effects were very low, $d<0.20$ (Cohen, 1992). 

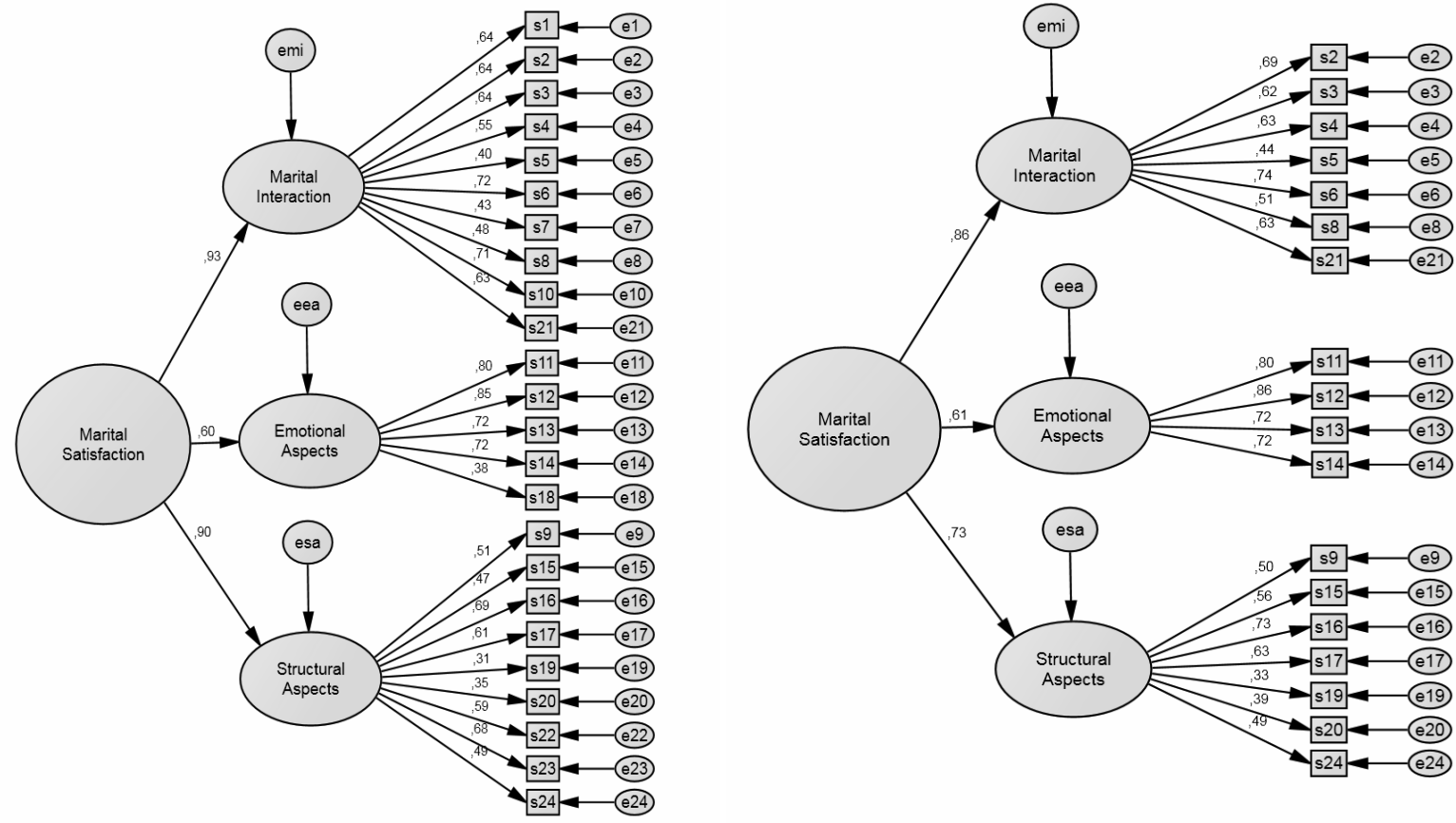

Figure 1. Diagrams of the original and abridged MSS models compared with their standardized estimations, respectively.

Table 5

Fit Indexes of the CFA for the Original and Abridged MSS Models

\begin{tabular}{lcccccc}
\hline Models & $\chi^{2} / d f$ & GFI & CFI & RMSEA (LO90-HI90) & AIC & CAIC \\
\hline Original (24 items) & 2.267 & 0.841 & 0.844 & $0.071(0.064-0.079)$ & 666.434 & 896.824 \\
Abridged (18 items) & 1.921 & 0.901 & 0.910 & $0.061(0.050-0.072)$ & 331.618 & 507.799 \\
\hline
\end{tabular}

For analysis purposes, the Number of Children variable was divided into four categories: no children, one child, two children, and three or more children. One-Way Variance Analysis for the Number of Children factor and the SMI, SEA, SSA and MSS $_{\text {total }}$ variables revealed substantial statistical differences between the mean scores of the groups compared in the SMI, $F_{(3}$ ${ }_{245)}=3.224, p<.05$, SSA, $F_{(3,245)}=3.013, p<.05$ and $\mathrm{MSS}_{\text {total }}, F_{(3,245)}=2.556, p<.05$ variables. The Hochberg post-hoc test identified the following differences between the groups that were compared: (a) With respect to the SMI and MSStotal variables, there were considerable differences between the no-children group of participants $(M=2.7, S D=0.36$ and $M=2.5, S D=0.32$, respectively) and the one-child group ( $M=2.4$, $S D=0.50$ and $M=2.3, S D=0.45$, respectively). Individuals with no children exhibited more SMI and $\mathrm{MSS}_{\text {total }}$ satisfaction with their spouses than those with only one child did. The effect sizes were $d=0.62$ and $d=0.56$, respectively. No noteworthy differences between the other groups were observed; and (b) As regards SSA, there was a considerable difference between the group of participants with three or more children $(M=$ $2.45, S D=0.44)$ and the group of those with only one child $(M=2.20, S D=0,52)$. Individuals with three or more children were more satisfied with their spouses' way of organizing, establishing, and complying with rules than participants with only one child were. The effect size was $d$ $=0.52$. No noteworthy differences between the other groups were observed.

Most of the participants $(n=182)$ had a university degree or an incomplete university education; the other educational levels consisted of only a few participants. It was thus not possible to assess the connections between educational levels and Marital Satisfaction. 


\section{Discussion}

In the present study, several MSS items were excluded because they exhibited higher loadings for factors that were not specified in the original model, presented cross-loadings or displayed insufficient factor loadings; some of these items coincide with the items of poor psychometric performance in Dela Coleta's studies (1989). Nonetheless, since the methods employed in the two studies are different, it is difficult to compare them. The present EFA extracted an 18item (seven for SSA, seven for SMI, and four for SEA) final solution that produced factor validity evidence for the MSS. This was corroborated by the CFA.

Pick de Weiss and Andrade Palos (1988a) did not employ the MSS as a global scale. However, Dela Coleta (1989, p. 107) advocated such a possibility, although her idea was based exclusively on the "reliability indices obtained" in her research. Employed in the present study, SSL is a resource that can contribute to elaborating the content of general (second-order) or specific (first-order) constructs, which are represented in measurement instruments. Information concerning the relative contributions of different levels of factors is of theoretical relevance because it reveals the correlation between specificity and generality. In the condensed MSS version (Table 4), the observed variables effectively represent the global construct, safeguarding the specific constructs. The CFA also indicated a good fit for the condensed MSS model with one general dimension. At the same time, the CFA revealed a fit considered tolerable (Marôco, 2014) for the original MSS model with 24 items (Table 5).

In the present study, by way of exploratory methods, we thus produced validity evidence for the factors of the abridged MSS with one global factor and three first-order factors. This factorrelated solution stood out due to its thriftiness, in light of the high degree of simplicity achieved (Bentler, 1977; Lorenzo-Seva, 2003). Furthermore, it exhibited a good fit $(\mathrm{GFI}=0.99)$ and the residuals were lower than expected (Kelley, 1935). The model's estimated reliability yielded very high values for all factors and for the general scale. Moreover, this abridged MSS model underwent CFA and demonstrated a good fit (Table 5).

Men evidenced greater SMI than women did in this study; however, the magnitude of this effect was moderate to small (Cohen, 1992). Pick de Weiss \& Andrade Palos (1988a, 1988b) and Rostami, Ghazinour, Nygren and Richter (2014) also observed greater satisfaction for men than for women.

One of the reasons for such discrepancies relates to the differences between women and men's roles in marriage. Women's roles are apparently more demanding and less gratifying than men's roles are. Women supposedly view their marriages less positively and feel as if they receive fewer advantages. Married women with full-time jobs are believed to face greater responsibilities, duties and role conflicts within their families (Rostami et al., 2014). Another reason is that women seem to expect more intimacy and emotional support than men do, and men are purportedly not socialized sufficiently to offer such support. Several researchers have discovered that a spouse's emotional support best predicts marital satisfaction (Mickelson, Claffey, \& Williams, 2006).

The class of biological theories posits that men and women process events in their relationships differently at the cardiovascular, endocrinological, immunological, neurosensory, and neurophysiological levels. Although men are more physiologically sensitive than women are to acute stressors, women demonstrate stronger and longer lasting physiological changes due to marital conflicts than men do (Kiecolt-Glaser \& Newton, 2001). Other researchers suggest that men and women differ in areas in which they faced different adaptive challenges during their respective evolutionary paths (Simpson \& Gangestad, 2001).

In contrast, Jackson et al. (2014) conducted a meta-analysis involving 226 samples and 101,110 individuals. The results revealed differences with a very slight effect: women were marginally less satisfied than men were. Further 
analyses revealed no differences when spouses' marital satisfaction levels were compared for the same relationship (dyadic data). To Kurdek (2005), it is possible that such sexual differences between men and women, with unrelated data, are due to skewed samples.

In the present study, for SMI and MSS the one-child situation exhibited a lower level of marital satisfaction than the no-children situation exhibited. We also discovered a considerable difference between the one-child and threeor-more-children situations in terms of SSA. This could be related to the transition to parenthood, a period involving the spouses' adaptation to their new roles as parents and professionals (Hernandez \& Hutz, 2009; Lawrence, Rothman, Cobb, \& Bradbury, 2010). After surmounting the impact of the first child, the next children would be absorbed with greater ease, in light of the fact that no noteworthy differences between the childless group and the two-children and three-or-more-children groups were detected. As a general rule, the existence of offspring can also limit the parents' freedom, especially when they have a career, which frequently involves hard and/or stressful work (Twenge, Campbell, \& Foster, 2003).

In the present study, reasonable evidence of factor validity, criterion validity and reliability, at the very least, were produced for the scores of the abridged MSS version. Nevertheless, the study's sample is a convenience sample and is limited to the metropolitan region of Rio de Janeiro. The results should thus be considered in light of the limited circumstances in which they were produced. Notwithstanding, the participants were ordinary citizens, whereas university samples are typically employed in this field of research. Furthermore, most of the examinees were middle-aged adults involved in long, effective marital relationships (marriages or civil unions), which are important factors when researching marital satisfaction. We thus recommend future studies involving larger, more diversified Brazilian samples that can contribute additional data to reinforce the MSS's structural validity.

\section{References}

Ahmadi, H., \& Sadeghi, M. (2016). The role of socio - Economic status in marital satisfaction. Turkish Journal of Psychology, 31(77), 43-47.

Arbuckle, (2009). Amos User's Guide. Chicago, IL: Statistical Product and Service Solutions.

Benetti, S. P. C. (2006). Conflito conjugal: Impacto no desenvolvimento psicológico da criança e do adolescente. Psicologia: Reflexão e Crítica, 19, 261-268. doi:http://dx.doi.org/10.1590/S010279722006000200012

Bentler, P. M. (1977). Factor Simplicity Index and Transformations. Psychometrika, 42(2), 277295. doi:10.1007/BF02294054

Bolsoni-Silva, A. T., \& Marturano, E. M. (2010). Relacionamento conjugal, problemas de comportamento e habilidades sociais de pré-escolares. Psicologia: Teoria e Prática, 26(1), 67-75.

Buja, A., \& Eyuboglu, N. (1992). Remarks on parallel analysis. Multivariate Behavioral Research, 27(4), 509-540. doi:10.1207/ s15327906mbr2704_2

Byrne, B. (2010). Structural Equation Modeling with AMOS. Basic Concepts, Applications, and Programming. New York: Routledge Taylor \& Francis Group.

Cohen, J. (1992). A Power Primer. Psychological Bulletin, 112(1), 155-159. doi:http://dx.doi. org/10.1037/0033-2909.112.1.155

Conway, J. M., \& Huffcutt, A. (2003). A review and evaluation of exploratory factor analysis practices in organizational research. Organizational Research Methods, 6(2), 147-168. doi:10.1177/1094428103251541

Costello, A. B., \& Osborne, J. W. (2005). Best practices in Exploratory Factor Analysis: Four recommendations for getting the most from your analysis. Practical Assessment, Research \& Evaluation, 10(7). Retrieved from http://pareonline.net/getvn.asp? $v=10 \& n=7$

Damásio, B. F. (2012). Uso da análise fatorial exploratória em psicologia. Avaliação Psicológica, 11(2), 213-228.

Dela Coleta, M. F. (1989). A Medida da Satisfação Conjugal: Adaptação de uma Escala. Psico, 18(2), 90-112.

Dela Coleta, M. F. (1992). Locus de controle e satisfação conjugal. Psicologia: Teoria e Pesquisa, $8,243-252$. 
Dominguez Lara, A. S. (2014). ¿ Matrices Policóricas/Tetracóricas o Matrices Pearson? Un estudio metodológico. Revista Argentina de Ciencias del Comportamiento, 6(1), 39-48.

Ferrando, P. J., \& Anguiano-Carrasco, C. (2010). El análisis factorial como técnica de investigación en psicología. Papeles del Psicólogo, 31(1), 1833.

Gaskin, C. J., \& Happell, B. (2014). On exploratory factor analysis: A review of recent evidence, an assessment of current practice, and recommendations for future use. International Journal of Nursing Studies, 51, 511-521. doi:http://dx.doi. org/10.1016/j.ijnurstu.2013.10.005

Gottman, J. M., \& Silver, N. (2000). The Seven Principles for Making Marriage Work: A Practical Guide from the Country's Foremost Relationship Expert. New York: Three Rivers Press.

Hair, J. F., Black, W. C., Babin, B. J., Anderson, R. E., \& Tatham, R. L. (2009). Análise Multivariada de Dados. Porto Alegre, RS: Bookman.

Henson, R. K., \& Roberts, J. K. (2006). Use of exploratory factor analysis in published research. Common errors and some comment on improved practice. Educational and Psychological Measurement, 66(3), 393-416.

Hernandez, J. A. E., \& Hutz, C. S. (2009). Transição para a parentalidade: Ajustamento conjugal e emocional. Psico, 40(4), 414-421.

Izquierdo, I., Olea, J., \& Abad, F. J. (2014). Exploratory factor analysis in validation studies: Uses and recommendations. Psicothema, 26(3), 395400. doi:10.7334/psicothema2013.349

Jackson, J. B., Miller, R. B., Oka, M., \& Henry, R. G. (2014). Gender differences in Marital Satisfaction: A Meta-analysis. Journal of Marriage and Family, 76(1), 105-129. doi:10.1111/ jomf. 12077

Kelley, T. L. (1935). Essential Traits of Mental Life, Harvard Studies in Education. Cambridge, MA: Harvard University Press.

Kiecolt-Glaser, J. K., \& Newton, T. L. (2001). Marriage and health: His and hers. Psychological Bulletin, 127(4), 472-503. doi:http://dx.doi. org/10.1037/0033-2909.127.4.472

Kurdek, L. A. (2005). Gender and Marital Satisfaction Early in Marriage: A Growth Curve Approach. Journal of Marriage and Family, 67(1), 68-84. doi:10.1111/j.00222445.2005.00006.x

Laros, J. A. (2005). O uso da análise fatorial: algumas diretrizes para pesquisadores. In L. Pasquali
(Ed.), Análise fatorial para pesquisadores (pp. 163-184). Brasília, DF: Laboratório de Pesquisa em Avaliação e Medida.

Lawrence, E., Rothman, A. D., Cobb, R. J., \& Bradbury, T. N. (2010). Marital satisfaction across the transition to parenthood: Three eras of research. In M. S. Schulz, M. K. Pruett, P. K. Kerig, \& R. D. Parke (Eds.), Strengthening couple relationships for optimal child development: Lessons from research and intervention (pp. 97114). Washington, DC: American Psychological Association.

Lorenzo-Seva, U. (2003). A factor simplicity index. Psychometrika, 68(1), 49-60. doi:10.1007/ BF02296652

Lorenzo-Seva, U., \& Ferrando, P. J. (2015). Manual of The Program FACTOR. Tarragona, Spain: Universitat Rovira i Virgili. Retrieved from http://psico.fcep.urv.es/utilitats/factor/index. html

Lorenzo-Seva, U., Timmerman, M. E., \& Kiers, H. A. L. (2011). The Hull method for selecting the number of common factors. Multivariate Behavioral Research, 46(2), 340-364. doi:10.1080/00 273171.2011.564527

Lloret-Segura, S., Ferreres-Traver, A., HernándezBaeza, A., \& Tomás-Marco, I. (2014). El análisis factorial exploratorio de los ítems: una guía práctica, revisada y actualizada. Anales de Psicología, 30(3), 1151-1169. doi:http://dx.doi. org/10.6018/analesps.30.3.199361

Machado, L. M. (2007). Satisfação e insatisfação no casamento: Os dois lados de uma mesma moe$d a$ ? (Master's thesis, Programa de Pós-Graduação em Psicologia, Universidade Federal de Uberlândia, MG, Brazil).

Mardia, K. V. (1970). Measures of multivariate skewness and kurtosis with applications. Biometrika, 57(3), 519-530. doi:10.2307/2334770

Marôco, J. (2014). Análise de Equações Estruturais. Fundamentos Teóricos, Software \& Aplicações. Pêro Pinheiro, Portugal: Report Number.

Mickelson, K. D., Claffey, S. T., \& Williams, S. L. (2006). The moderating role of gender and gender role attitudes on the link between spousal support and marital quality. Sex Roles, 55(1), 73-82. doi:10.1007/s11199-006-9061-8

Mihalcea, A., Iliescu, D., \& Dincă, M. (2013). The Influence of the Educational Level on Couple Relationships. Procedia - Social and Behavioral Sciences, 78, 41-45. doi:10.1016/j.sbspro.2013.04.247 
Minnotte, K. L., Minnotte, M. C., \& Pedersen, D. E. (2013). Marital satisfaction among dual-earner couples: Gender ideologies and family-to-work conflict. Family Relations, 62(4), 686-698. doi:10.1111/fare.12021

Mirecki, R. M., Chou, J. L., Elliott, M., \& Schneider, C. M. (2013). What factors influence marital satisfaction? Differences between first and second marriages. Journal of Divorce \& Remarriage, 54(1), 78-93. doi:http://dx.doi.org/10.1080/105 02556.2012 .743831

Norgren, M. B. P., Souza, R. M., Kaslow, F., Hammerschmidt, H., \& Sharlin, S. A. (2004). Satisfação conjugal em casamentos de longa duração: Uma construção possível. Estudos de Psicologia (Natal), 9(3), 575-584. doi:http://dx.doi. org/10.1590/S1413-294X2004000300020

Oliveira, M. G. S., Falcone, E. M. de O., \& Ribas, R. C., Jr. (2009). A avaliação das relações entre a empatia e a satisfação conjugal: Um estudo preliminar. Interação em Psicologia, 13(2), 287-298. doi:http://dx.doi.org/10.5380/psi. v13i2.8025

Pick de Weiss, S., \& Andrade Palos, P. (1988a). Desarrolllo y validacion de la Escala de Satisfaccion Marital. Psiquiatria, 1, 9-20.

Pick de Weiss, S., \& Andrade Palos, P. (1988b). Diferencias sociodemográficas en la satisfacción marital: el caso de México. Revista de Psicología Social, 3, 91-97.

Pick de Weiss, S., \& Andrade Palos, P. (1988c). Relación entre el número de hijos, la satisfacción marital y la comunicación con el cónyuge. Salud Mental, 11, 15-18.

Ribeiro, C. M., Pinho, V. D., \& Falcone, E. M. O. (2011). A influência da raiva e da empatia sobre a satisfação conjugal. Aletheia, 35-36, 7-21.

Rostami, A., Ghazinour, M., Nygren, L., \& Richter, J. (2014). Marital satisfaction with a special focus on gender differences in medical staff in Tehran, Iran. Journal of Family Issues, 35(14), 19401958. doi:10.1177/0192513X13483292

Sardinha, A., Falcone, E. M. O., \& Ferreira, M. C. (2009). As relações entre a satisfação conjugal e as habilidades sociais percebidas no cônjuge. Psicologia: Teoria e Pesquisa, 25(3), 329-336. doi:http://dx.doi.org/10.1590/S010237722009000300013

Schmid, J., \& Leiman, J. N. (1957). The development of hierarchical factor solutions. Psychometrika, 22, 53-61. doi:10.1007/BF02289209
Sbicigo, J. B., \& Lisbôa, C. S. de M. (2009). Habilidades sociais e satisfação conjugal: Um estudo correlacional. Revista Brasileira de Terapias Cognitivas, 5, 73-81.

Scorsolini-Comin, F., \& Santos, M. A. (2011a). Relações entre bem-estar subjetivo e satisfação conjugal na abordagem da psicologia positiva. Psicologia: Reflexão e Crítica, 24, 658-665. doi:http://dx.doi.org/10.1590/S010279722011000400005

Scorsolini-Comin, F. \& Santos, M. A. (2011b). Ajustamento diádico e satisfação conjugal: Correlações entre os domínios de duas escalas de avaliação da conjugalidade. Psicologia: Reflexão e Crítica, 24(3), 439-447. doi:http://dx.doi. org/10.1590/S0102-79722011000300007

Scorsolini-Comin, F., \& Santos, M. A. (2012). A medida positiva dos afetos: Bem-estar subjetivo (BES) em pessoas casadas. Psicologia: Reflexão e Crítica, 25, 11-20. doi:http://dx.doi. org/10.1590/S0102-79722012000100003

Simpson, J. A., \& Gangestad, S. W. (2001). Evolution and relationships: A call for integration. Personal Relationships, 8(4), 341-355. doi:10.1111/j.1475-6811.2001.tb00044.x

Solomon, B. C., \& Jackson, J. J. (2014). Why do personality traits predict divorce? Multiple pathways through satisfaction. Journal of Personality and Social Psychology, 106(6), 978-996. doi:http://dx.doi.org/10.1037/a0036190

Timmerman, M. E., \& Lorenzo-Seva, U. (2011). Dimensionality assessment of ordered polytomous items with parallel analysis. Psychological Methods, 16(2), 209-220. doi:10.1037/a0023353

Twenge, J., Campbell, K., \& Foster, C. (2003). Parenthood and marital satisfaction: A metaanalytic review. Journal of Marriage and Family, 65(3), 574-583. doi:10.1111/j.17413737.2003.00574.x

Villa, M. B., \& Del Prette, Z. A. P. (2013). Marital satisfaction: The role of social skills of husbands and wives. Paidéia (Ribeirão Preto), 23(56), 379-388. doi:http://dx.doi.org/10.1590/198243272356201312

Wolff, H.-G., \& Preising, K. (2005). Exploring item and higher order factor structure with the Schmid-Leiman solution: Syntax codes for SPSS and SAS. Behavior Research Methods, 37, 48-58. doi:10.3758/BF03206397

Received: 16/05/2016

$1^{\text {st }}$ revision: $17 / 12 / 2016$

Accepted: 28/12/2016 